\title{
A limited survey of aflatoxins and zearalenone in feed and feed ingredients from Pakistan
}

\begin{abstract}
This work presents current information on the presence of aflatoxins (AFs) and zearalenone (ZEN) in feed and feed ingredients from Punjab, Pakistan. The 105 samples tested were concentrated feed, i.e., cotton seed meal (18 samples) and soybean meal (14), and feed ingredients, i.e., crushed corn (17), crushed wheat (15), barley (17). and poultry feed (24). Samples were analyzed using high-performance liquid chromatography equipped with a fluorescence detector. Analysis revealed that 69 of 105 samples were contaminated with AFs, and the highest mean concentrations of $\mathrm{AFB}_{1}(6.20 \mu \mathrm{g} / \mathrm{kg})$ and total AFs $(9.30 \mu \mathrm{g} / \mathrm{kg})$ were found in poultry feed samples. The mean total AF concentrations ranged from the limit of quantification to $165.5 \mu \mathrm{g} / \mathrm{kg}$. However, 75 of the 105 samples were positive for ZEN. The highest mean concentration $(19.45 \mu \mathrm{g} / \mathrm{kg})$ was found in poultry feed samples. The mean ZEN concentrations were 0.15 to $145.30 \mu \mathrm{g} / \mathrm{kg}$. The prevalence of AFs and ZEN was high in feed and feed ingredients and needs urgent attention.
\end{abstract}

Keyword: Aflatoxins; Zearalenone; Feed and feed ingredients; HPLC 